\title{
THE DYNAMIC LIGHTING INTO THE WORKING ENVIRONMENT
}

\author{
F. PATANIA ${ }^{* 1}$, A. GAGLIANO ${ }^{* 1}$, F. NOCERA ${ }^{* 2}$, A. GALESI $^{* 1}, \&$ J.CASERTA $^{2}$ \\ *Energy and Environment Division of D.I.I.M. \\ ${ }^{1}$ Engineering Faculty of University of Catania, Catania, Italy. \\ ${ }^{2}$ Architecture Faculty of University of Catania, Catania, Italy.
}

\begin{abstract}
The light exercises indeed a very significant influence on whole biological parameters of people. If in the recent past the emphasis has been primarily focused on the visual effects of lighting, for the new projects the efforts of researcher are focused in discovering the psychological and biological effects of the lighting on people such as the relationship between men, the well-being status of people like body temperature, alertness and so on. The 'dynamic lighting' is an advanced technique that tries to bring the dynamic of daylight in indoor environments with the aim to create a stimulating 'natural' light that may enhances people's sense of well-being. By this technique, people could control their own space according to their needs, mood and task, to improve performance and motivation of their own job, creating the right atmosphere by 'Dynamic Light Scenario': 'personal light' or 'dynamic ambience'. According to this objective, the authors have applied the dynamic light technique in different environments as offices, museum and exhibitions halls. The aim of the paper is to show the results obtained in terms of human comfort, energy consumption and installation cost of the dynamic lighting systems. Keywords: comfort, dynamic light, minimalist architecture, well-being.
\end{abstract}

\section{BIOLOGICAL EFFECTS OF LIGHT}

\subsection{Introduction}

Over 150 years since the discovery of the retinal rod and cone photoreceptors in 1834 , it has been believed that, both visual and biological effects induced by light would be dependent on these two traditional photoreceptors. However in 2002, through the discovery of a novel photoreceptor in the eye by David Berson et al. [1] views have changed on how human vision system works. The novel photoreceptor, an intrinsically photosensitive retinal ganglion cell (ipRGC) is one of the known 20 ganglion cells in human retina. It has been estimated that of all retinal ganglion cells (RGC), $0.25 \%$ are photosensitive ipRGCs [2]. It was found [3] that the novel photoreceptor is responsible mainly for regulating light-induced human biological rhythms (circadian rhythms) by synchronising body to environmental light/dark cycle. It has also been proposed [4] to mediate light-induced increase in alertness, pupillary responses and as a possible target for seasonal depression treatment. This novel photoreceptor may have many consequences for practical applications both in general lighting and lighting for special groups (e.g. elderly, shift workers and patients suffering from seasonal depression) so it has become a great interest of research in the lighting community [5].

\subsection{Hormone levels}

The best documented effect of light exposure on endocrine functions is the suppression of nocturnal melatonin [6] occurring within minutes of exposure to bright light [7]. The effects to other hormone levels are less well documented. Some studies [8] have found elevated cortisol levels after bright light independent of the exposure timing but, according to current knowledge, it seems that these 
effects are due to environmental variables rather than bright light. However, it is known that a pulse in cortisol secretion consistently follows the sleep/wake transition regardless of the time of the day $[9,10]$ while the light/peak connection has not been conclusively identified. In a study of simulated jet lag, the shifted sleep period was consistently followed by a sharp rise of plasma TSH (thyrotropin) levels [11].

Leproult et al. [12] examined the secretion patterns of these three hormones (melatonin, cortisol and TSH) under three different conditions (dim light; afternoon bright light after 30 hours of wakefulness and early morning bright light, after 20 hours of wakefulness) using the constant routine (CR) protocol. Results showed similar TSH profiles in all three conditions and there were no significant effects of exposure to bright light. Melatonin levels also showed expected behavior with a clear nocturnal peak and a significant suppression during early morning light. Also as expected, no melatonin suppression was found during afternoon bright light exposure as melatonin levels were already very marginal. Robust effect of bright light to morning cortisol levels was noticed, but not in the afternoon.

The rapid elevations in cortisol levels after early morning transition from dim to bright light did not appear related to an acute stress effect as no increase in heart rate was observed.

However, it should be noticed that the function of awakening cortisol response (ACR) $[13,14]$ is not yet very well known in general. According to a recent review by Clow et al. [15] it still remains unclear whether a positive affect and good health are consistently associated with larger or smaller awakening responses. According to current knowledge [16] it would not be justified suggesting that high light-induced cortisol levels make you healthier or perform better in long term. Higuchi et al. [17] conducted an interesting experiment on the effects of bright video display terminals (VDT) on nocturnal melatonin levels. According to a Japanese white paper on information technology [18], $53.7 \%$ of Internet users in Japan had delayed bedtimes and $45.4 \%$ of them had shortened sleeping hours. These statistics suggested that performing a VDT task could influence the sleep/wake cycle and circadian rhythms.

Additionally, it has been noticed that exercise $[19,20]$ and affective state could affect melatonin levels implying an increased mental activity: for example by exciting a computer game could have a synergistic effect with light from VDT. Four different study conditions were used: exciting (shooting game) VDT tasks with bright display (exciting-BD) and dark display (exciting-DD), and boring (simple addition) VDT tasks with bright display (boring-BD) and dark display (boring-DD) between 23:00 and 02:00. The screen luminance of white BD was $120 \mathrm{~cd} / \mathrm{m}^{2}$ and of the black DD was $0.5 \mathrm{~cd} / \mathrm{m}^{2}$. The lighting in the experimental room was $\operatorname{dim}(<10 \mathrm{~lx})$ making the corresponding vertical illuminance for BD $45 \mathrm{~lx}$ and for DD $15 \mathrm{~lx}$.

\subsection{Biological clock}

The most important findings are related to the control of the biological clock and to the regulation of some important hormones through regular light/dark rhythms.

This in turn means that lighting has a large influence on health, well-being and alertness. Light sends signals via the novel photoreceptor cells and a separate nerve system to our biological clock, which in turn regulates the circadian (daily) and circannual (seasonal) rhythms of a large variety of bodily processes. Figure 1 shows some typical rhythms in human beings. The figure shows only a few examples: body temperature, alertness, and the hormones cortisol and melatonin [21].

The hormones cortisol ('stress hormone') and melatonin ('sleep hormone') play an important role in governing alertness and sleep. It is the rhythm of day and night, of light and darkness that synchronises our biological clock. Accordingly, light has a direct and significant impact on people's alertness and well-being. 


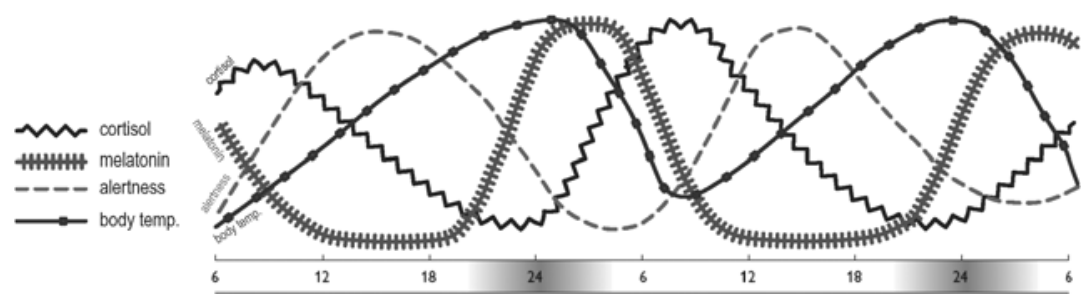

Figure 1: Some typical rhythms in human beings.

So, while the emphasis in the past may have been primarily on the visual effects of lighting, now there is increasing interest in its biological effects too. It is possible, therefore, to use daily dynamics in lighting to improve performance, for example, by varying illuminance and colour temperature according to the time of day. Higher illuminance levels with colder light will wake us up in the morning and make us more alert during the post-lunch dip. Low illuminances with a warm colour temperature have a calming effect. Two of the characteristics of light that strongly influence how we feel in a given environment are the brightness and colour appearance of the light. First of all, the light should always be bright enough to facilitate visual task performance, and obviously, a better visual task performance results in a better work performance. Increased lighting levels can also help to counteract well-known effects such as the 'after-lunch dip' among day workers [22].

The colour appearance of the light has substantial biological relevance too. For example, the bluish light of morning has a stimulating effect on us, while the red sky of the early evening is relaxing. Daylight - the form of light with which we are most comfortable - is never constant. It changes throughout the day, affecting our emotions, moods, perception and performance [23, 24].

\subsection{Dynamic lighting}

During the course of the day the position of the sun and the colour temperature of natural light change. Dynamic lighting takes in account of these changes and is increasingly replacing static lighting solutions for indoor applications.

This is possible thanks to intelligent control and sensor technology. Luminaires that radiate direct and indirect light simultaneously, for example, can be fitted with separately controllable light sources of different light colours. Governed by a lighting management system, they can thus deliver light with a changing colour temperature designed to support our natural biological rhythms.

A good lighting installation tailors illuminance to the visual task and distributes luminance evenly in the room. It limits direct and reflected glare and has good colour rendering properties.

The basic requirements are set out in the standard DIN EN 12464-1 'Light and lighting - Lighting of work places'. This 'recommendation' defines minimum values for the relevant lighting variables and minimum requirements for good lighting quality.

A lighting installation for biologically effective lighting also needs to ensure that light colour and direction of light are right for the conditions.

Light colour is expressed as a colour temperature in Kelvin and it indicates the intrinsic colour of the light emitted by a lamp. The colour temperature of the sky varies mostly between 6000 and 10,000 Kelvin.

Light colour is crucial. The different colour temperatures of fluorescent lamps depend on the mix of phosphors in the tube. These have different spectral distributions which impact differently on the human circadian system. Light with a higher blue content, for example, is more circadian-effective 
than warm white light. Light colour is not the only variable important for biologically effective lighting. Our eyes need to be able to perceive bright areas in the room as effectively as possible. This is achieved by using large-area luminaires to brighten the space. Alternatively, luminaires with indirect beams can be used to illuminate the ceiling and the upper third of the walls. The activating effect of light is normally required only during the day. Warm light colours should be selected in the evening. The visible brightness in the upper part of the room can then also be reduced. For dynamic lighting, care needs to be taken to ensure that the spectrum of the light radiated by the lamp is not negatively influenced by the ambient colours in the room. Lamp light is altered in luminaires, especially by optical control elements such as louvers, enclosures or prisms. This may result in the light that reaches the eye having a different spectral composition than that radiated by the lamp. The spectral properties of optical control elements determine the quality of dynamic lighting. Where components are exposed for long times at high temperatures to light with a greater blue content, consideration also needs to be given to their ageing resistance. In the common case of LEDs with plastic lens systems, transmission properties in the blue spectral region need to be maintained over the entire life of the light source. The impression of a room is significantly influenced not only by the light colour of the lamps but also by the colours of the furniture, walls and ceiling. Dark colours reflect less light than light ones. A great deal of light can be 'lost' here, especially where light is sent exclusively on room surfaces by indirect luminaires. Wood finishes or reds and browns actually absorb the blue content of the spectrum and thus considerably reduce the biological effect of the lighting.

\section{THE KUNSTHALLE}

The authors have designed a dynamic lighting system for a 'Kunsthalle', an exhibition space dedicated to contemporary art, Fig. 2. The Kunsthalle was designed to find a balanced relationship

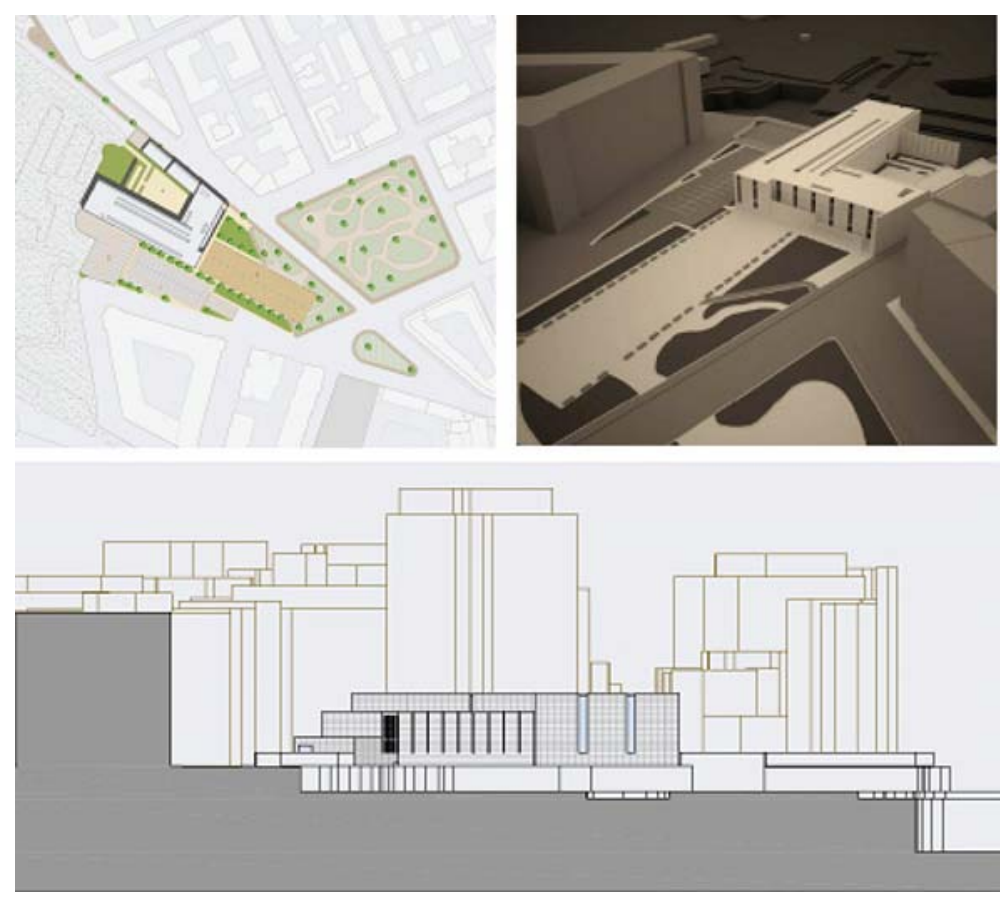

Figure 2: Some views of the Kunsthalle. 
between art, architecture and nature. The idea was to create a hinge structure 'hybrid' that confers a specific urban identity to the archaeological area of Syracuse, creating a zone filter to the archaeological site of Neapolis, carrying out a connection between the city and the archaeological zone. The project has drawn inspiration from minimalist architects like Claudio Silvestrin and Tadao Ando.

In the following sections, a detailed analysis of the comparison between a standard and a dynamic lighting system for the office located in the Kunsthalle is performed and the technical light design, the lighting parameters, the costs and benefits of the lighting systems are evaluated. Then, it will be shown how the technical light design, applied to the environment taken as a reference, can be applied to an exhibition hall, a gallery and anhe assembly room.

\section{STANDARD AND DYNAMIC LIGHTING SYSTEMS FOR AN OFFICE}

In a first step, respecting the limits imposed by current European regulations (EN 12464-1), the lighting design of the office located in the Kunsthalle was carried out using first the standard lighting system and then the dynamic lighting system. The office is an open space and its dimensions are $17.5 \mathrm{~m} \times 5.6 \mathrm{~m} \times 3.7 \mathrm{~m}$ (Fig. 3). The office has windows of size $0.2 \mathrm{~m} \times 1.70 \mathrm{~m}$ at a height of $2.0 \mathrm{~m}$ above the floor. The reflection coefficient of the walls is 0.5 . The reflection coefficient of ceiling is 0.7 . The reflection coefficient of the floor is 0.2 . The desks and the other furniture have a reflection coefficient equal to 0.3 .

The office lighting equipment has been arranged in three rows of six Philips-type lighting fixtures, Savio model, version for mounting on the ceiling containing lamps 54W (TCS760-2xTL5-54W/840 Standard Lighting version and TCS770-3xTL5-54W/865/827/865 Dynamic Lighting version) with micro-lens optic (MLO) that allows omni-directional luminance control (OLC), placed parallel to the facade. The horizontal illuminance level has been calculated, both for the standard scenario and the dynamic scenario using the human rhythm (Fig. 4), and not taking into account the day-lighting (Figs. 5, 6), using the software Relux.

Table 1 shows a summary of the results obtained using the software Relux for the two scenarios. The different values of total luminous flux of all lamps and, consequently, the different values of average illuminance are due to both the use of different types of lamps to maintain the same uniformity of illumination for the two scenarios. It can be noted the minimum value of average illuminance, required by EN 12464-1, is satisfied for both scenarios but in the dynamic scenario, with the same rate of luminous flux, the average illuminance is greater of $300 \mathrm{~lx}$ compared with the standard scenario.

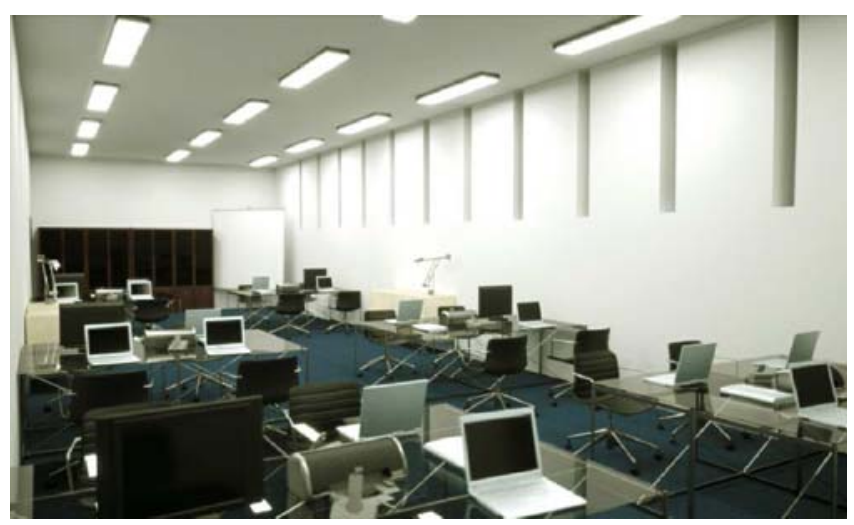

Figure 3: The office modelled with standard lighting. 


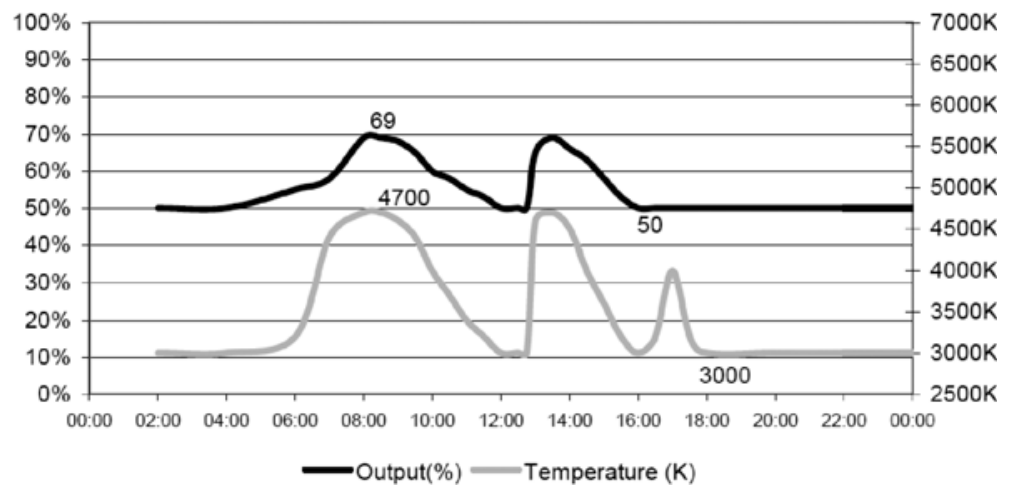

Figure 4: The graphs show the minimum and maximum values for both light output as well as colour temperature.

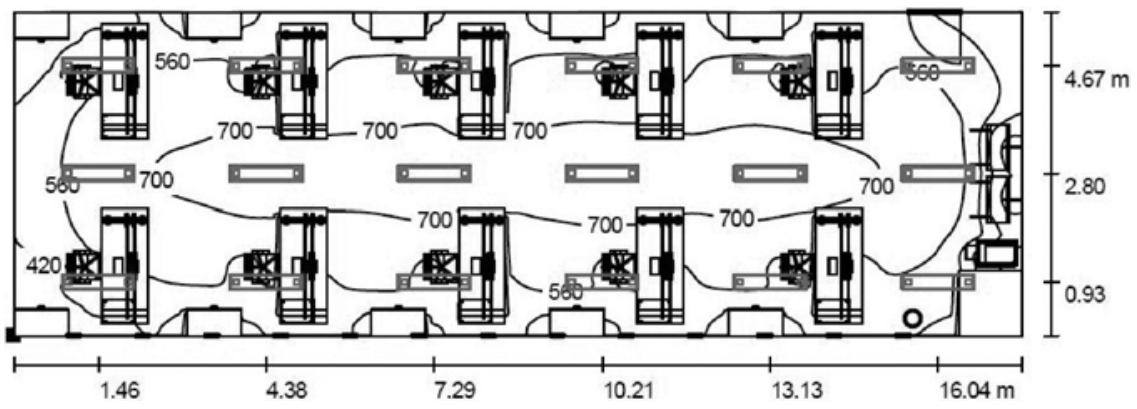

Figure 5: Horizontal illuminance levels for the standard scenario.

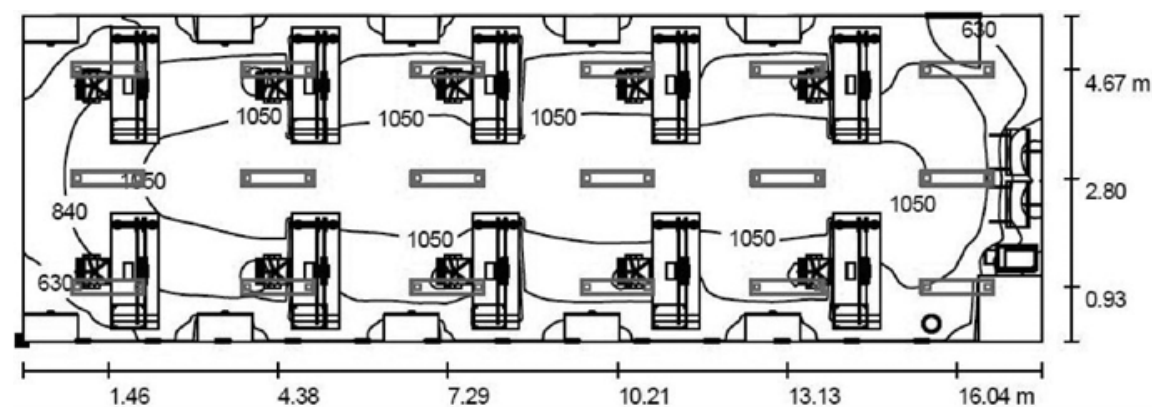

Figure 6: Horizontal illuminance levels for the dynamic scenario.

Tables 2 and 3 show that the values of the luminous flux and the colour temperature remain constant over time for the standard scenario, while these values change over time for the dynamic scenario. Moreover, in the two tables the cost of electricity is set out over a year for both scenarios. The cost of electricity for the dynamic scenario is $12 \%$ greater than the standard one.

The cost of the two lighting systems is quite the same while the cost of the lighting fixtures varies between the standard system and the dynamic system. The last one system in fact requires also both 
Table 1: Comparison between standard and dynamic scenario (Relux data).

\begin{tabular}{lll}
\hline & Standard Scenario & Dynamic Scenario \\
\hline Calculation algorithm used & High indirect fraction & \\
Height of evaluation surface & 0.75 & \\
Height of luminaire plane & 3.70 & \\
Maintenance factor & 0.80 & $233,118 \mathrm{~lm}$ \\
Total luminous flux of all lamps & $160,200 \mathrm{~lm}$ & $3204 \mathrm{~W}$ \\
Total power & $2124 \mathrm{~W}$ & $32.69 \mathrm{~W} / \mathrm{m}^{2}$ \\
Total power per area $\left(98.00 \mathrm{~m}^{2}\right)$ & $21.67 \mathrm{~W} / \mathrm{m}^{2}$ & $9101 \mathrm{x}$ \\
Average Illuminance $\left(E_{m}\right)$ & $590 \mathrm{~lx}$ & $1401 \mathrm{x}$ \\
Minimum Illuminance $\left(E_{\min }\right)$ & $91 \mathrm{~lx}$ & $1140 \mathrm{~lx}$ \\
Maximum Illuminance $\left(E_{\max }\right)$ & $742 \mathrm{~lx}$ & 0.15 \\
Uniformity $\left(E_{\min } / E_{m}\right)$ & 0.15 & 0.12 \\
Uniformity $\left(E_{\min } / E_{\max }\right)$ & 0.12 & \\
\hline
\end{tabular}

Table 2: Illuminance levels, luminous flux, colour temperature and cost for the standard scenario.

\begin{tabular}{lccccccc}
\hline \multicolumn{8}{c}{ Standard Lighting } \\
\hline $\mathrm{h}$ & $E_{m}[\mathrm{~lx}]$ & Flux & Tcp $[\mathrm{K}]$ & $\mathrm{P}[\mathrm{kW}]$ & h/year & $€ / \mathrm{kWh}$ & $€ /$ year \\
\hline 8:00/18:00 & 590 & $100 \%$ & 4000 & 2.124 & 2400 & 0.13 & 662.69 \\
\hline
\end{tabular}

Table 3: Illuminance levels, luminous flux, colour temperature and for the dynamic scenario.

\begin{tabular}{lccccccc}
\hline \multicolumn{7}{c}{ Dynamic Lighting } \\
\hline $\mathrm{h}$ & $E_{m}[\mathrm{~lx}]$ & Flux & Tcp $[\mathrm{K}]$ & $\mathrm{P}[\mathrm{kW}]$ & $\mathrm{h} /$ year & $€ / \mathrm{kWh}$ & $€ /$ year \\
\hline $8: 00$ & 709 & $78 \%$ & 4400 & 2.499 & 240 & 0.13 & 77,972 \\
$9: 00$ & 709 & $78 \%$ & 4400 & 2.784 & 240 & 0.13 & 86,860 \\
$10: 00$ & 873 & $96 \%$ & 3800 & 2.816 & 240 & 0.13 & 87.859 \\
$11: 00$ & 728 & $80 \%$ & 3500 & 3.304 & 240 & 0.13 & 71.884 \\
$12: 00$ & 582 & $64 \%$ & 3000 & 2.080 & 240 & 0.13 & 64.896 \\
$13: 00$ & 591 & $65 \%$ & 4900 & 2.080 & 240 & 0.13 & 64.896 \\
$14: 00$ & 591 & $65 \%$ & 4900 & 3.304 & 240 & 0.13 & 71.884 \\
$15: 00$ & 728 & $80 \%$ & 4250 & 2.400 & 240 & 0.13 & 74.880 \\
$16: 00$ & 637 & $70 \%$ & 4500 & 2.560 & 240 & 0.13 & 79.872 \\
$17: 00$ & 819 & $90 \%$ & 4000 & 2.560 & 240 & 0.13 & 79.872 \\
$18: 00$ & 728 & $80 \%$ & 4250 & 2.499 & 240 & 0.13 & 77.972 \\
Total & & & & & & & 760.87 \\
\hline
\end{tabular}


a control unit and a set of modulation device. Consequently, the cost of a dynamic lighting system is greater than $44 \%$ compared with the standard lighting system. Table 4 shows the cost of the lighting fixtures for the two systems. The cost comparison has been done for 32 luminaires because it is the maximum number of luminaires that the controller can handle and it is convenient to handle the maximum possible number of luminaires.

Although the cost of a dynamic system is greater than that of the standard, some of the economic losses of a company are caused by the absence of the employees and this is not due to a healthy lighting. We consider that this part of economic loss attributed to the absence of the workers could have been transformed into an economic gain for the company by using a system of dynamic lighting. In fact, the research shows that one of the positive effects induced by the increase on well-being produced by a dynamic lighting is the decrease of the absenteeism that can be quantified from $8 \%$ to $12 \%$ [1]. The reduction in absenteeism could lead the company to an economic gain and it could help to offset the cost of investments over time. Figure 7 shows the cost of construction and management (annual energy and maintenance costs) for the dynamic system and standards.

The graph also shows the economic trend of the investment due to lower percentages of nonabsenteeism $(8 \%, 10 \%$ and $12 \%)$ thanks to the dynamic lighting system.

The below chart has taken into account the following program of maintenance:

- maintenance of lamps: 3rd, 5th, 9th, 11th, 13th year;

- maintenance and replacement of lamps: 7th year.

Table 4: The cost comparison of the lighting fixtures.

\begin{tabular}{lrrr}
\hline & Cost $(€)$ & N & Total $(€)$ \\
\hline $\begin{array}{l}\text { Standard Lighting } \\
\text { Luminaire TCS760 }\end{array}$ & 530 & 32 & 16,960 \\
& & & \\
Dynamic Lighting & & & \\
Luminaire TCS770 & 800 & 32 & 25,600 \\
Kit Dynamic Lighting & 4000 & 1 & 4000 \\
Control unit & 700 & 1 & 700 \\
\hline
\end{tabular}

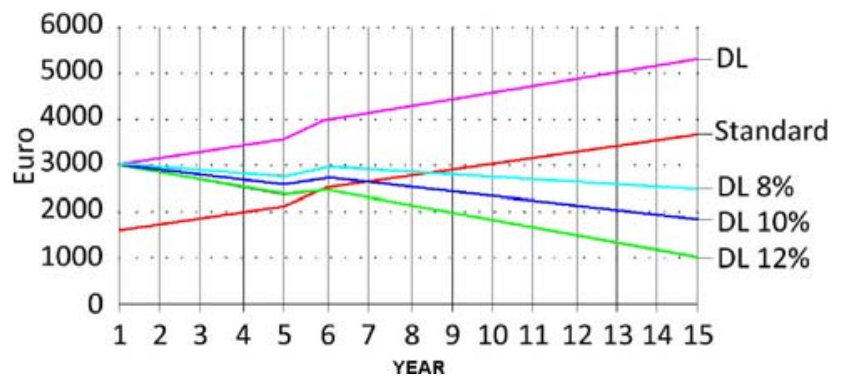

Figure 7: The cost of construction and management. 


\section{THE EXHIBITION HALL}

As mentioned in the previous section, the modelling of the exhibition hall is performed applying both the standard lighting system and the dynamic lighting system. In this case, however, we focused on a software capable of modelling the dynamic light. To this aim several simulations were performed with Fryrender software. Fryrender is a photo-realistic rendering engine where all the elements involved in the generation of the final image (materials, lights and cameras) are based on physically accurate models. It is not a classical rendering engine, but a physics simulator that reproduces the governing Laws of light radiation and optics accurately. This light simulation is performed using unbiased integration techniques that ensure the rendering will converge to the exact real light balance, provided there is enough time for the computations.

In the dynamic lighting simulation, the exhibition hall equipment has been arranged in two rows of twenty-eight Philips type lighting fixtures, Savio model, version for mounting on the ceiling containing lamps 35W (TCS770-3xTL5-54W/865/827/865). In the standard lighting simulation, the exhibition hall equipment has been arranged in four rows of fourteen Zumtobel-type lighting fixtures, SLOT model, version for mounting on the ceiling containing lamps 54W (Slot 3x1 54W PMMA LDE IP54). It has been calculated the horizontal and vertical illuminance level both for the standard scenario and the dynamic scenario using the human rhythm and not taking into account the day-lighting using the software Relux and then modelling the environment using the software Fryrender. Table 5 shows the comparison of the summary of results obtained in the two scenarios. Figure 8 shows four frames of the simulation of dynamic lighting with natural biorhythm. Figure 9 shows the image of the simulation of standard lighting. Figure 10 shows the comparison of the variation of dynamic lighting with the standard lighting

\section{THE GALLERY}

As mentioned in the previous section, the modelling of the gallery was performed applying both the standard lighting system and the dynamic lighting system.

In the dynamic lighting simulation, the gallery equipment was arranged in one row of fortyeight Philips type lighting fixtures, Savio model, version for mounting on the ceiling containing

Table 5: Comparison between the standard and dynamic scenarios (Relux data).

\begin{tabular}{lll}
\hline & Standard Scenario & Dynamic Scenario \\
\hline Calculation algorithm used & High indirect fraction & \\
Height of evaluation surface & 1.75 & \\
Height of luminaire plane & 7.90 & \\
Maintenance factor & 0.80 & $532056 \mathrm{~lm}$ \\
Total luminous flux of all lamps & $747600 \mathrm{~lm}$ & $6496 \mathrm{~W}$ \\
Total power & $9945.6 \mathrm{~W}$ & $9.34 \mathrm{~W} / \mathrm{m}^{2}$ \\
Total power per area $\left(695.72 \mathrm{~m}^{2}\right)$ & $14.30 \mathrm{~W} / \mathrm{m}^{2}$ & $311 \mathrm{~lx}$ \\
Average Illuminance $\left(E_{m}\right)$ & $311 \mathrm{~lx}$ & $111 \mathrm{~lx}$ \\
Minimum Illuminance $\left(E_{\text {min }}\right)$ & $122 \mathrm{~lx}$ & $413 \mathrm{~lx}$ \\
Maximum Illuminance $\left(E_{\text {max }}\right)$ & $397 \mathrm{~lx}$ & 0.36 \\
Uniformity $\left(E_{\text {min }} / E_{m}\right)$ & 0.39 & 0.27 \\
Uniformity $\left(E_{\text {min }} / E_{\text {max }}\right)$ & 0.31 & \\
\hline
\end{tabular}



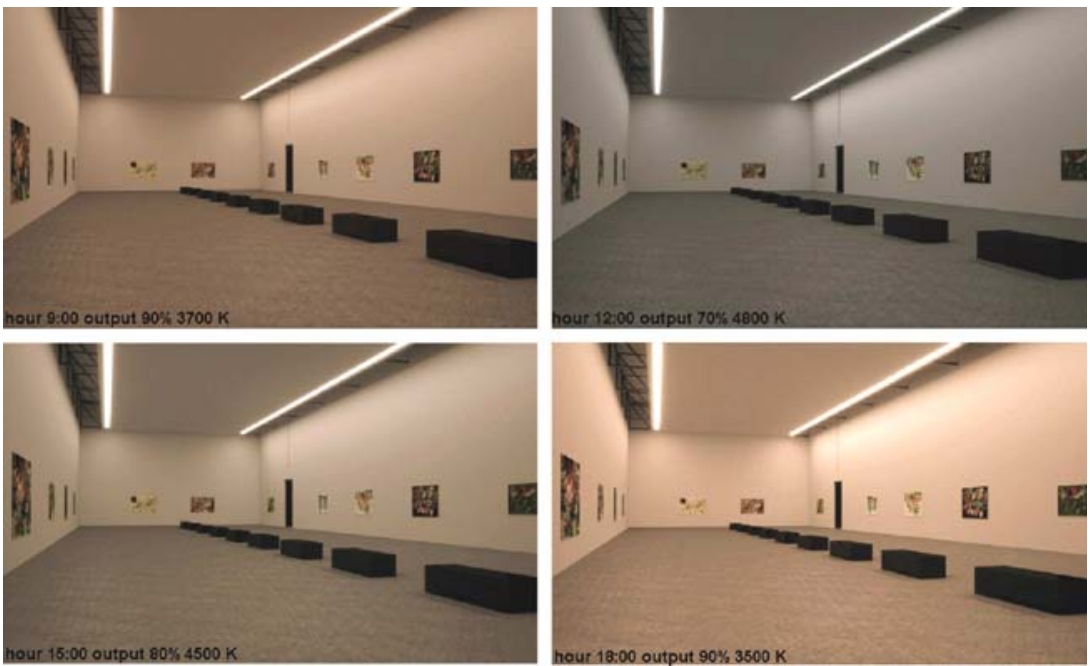

Figure 8: The images of exhibition hall with dynamic lighting system at different hours of the day.

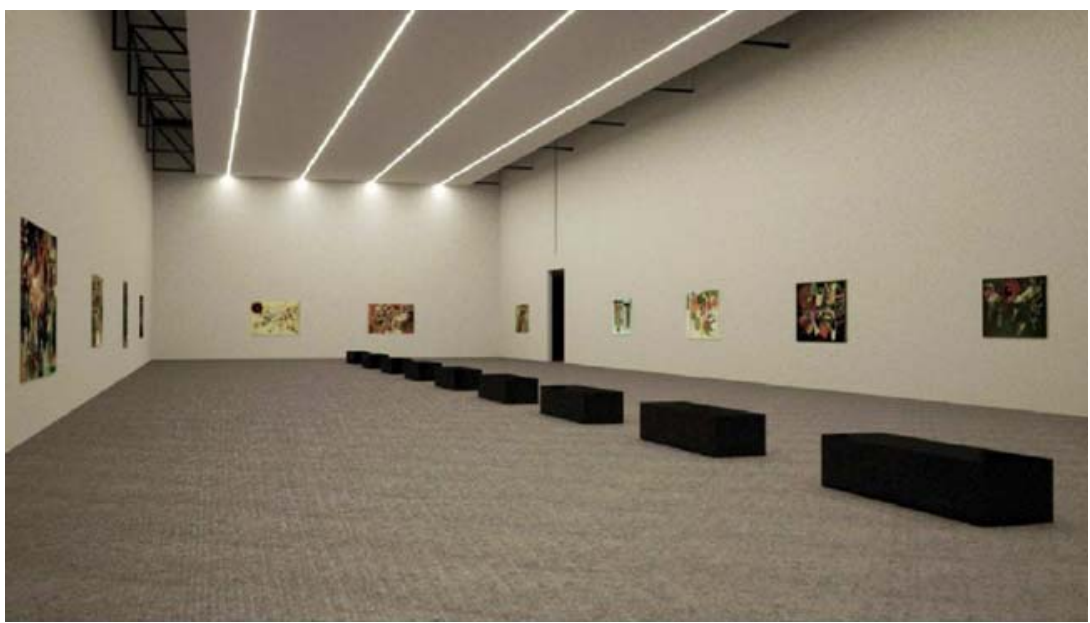

Figure 9: The images of exhibition hall with standard lighting system.

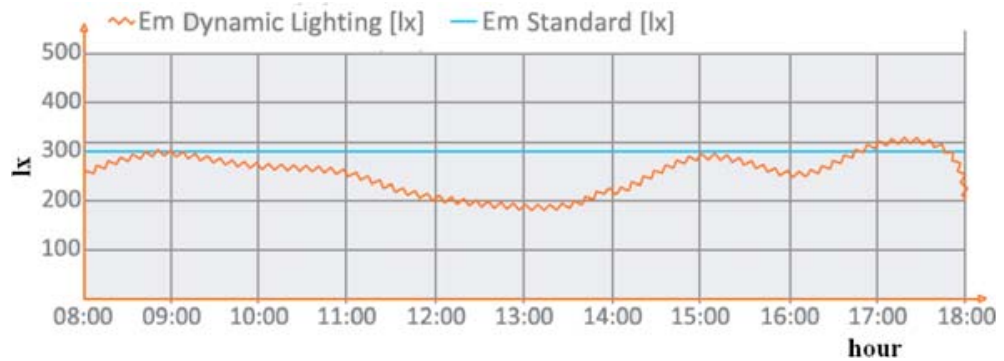

Figure 10: Comparison of illuminance between the dynamic lighting trend and standard lighting system. 
lamps 50W (TCS770-2xTL5-25W HFP AC-MLO). In the standard lighting simulation, the gallery equipment has been arranged in two rows of twenty-seven Zumtobel type lighting fixtures, SLOT model, version for mounting on the ceiling containing lamps 49W (Slot 3x1 49W PMMA LDE IP54). The horizontal and vertical illuminance levels were calculated both for the standard scenario and the dynamic scenario using the human rhythm, and not taking into account the daylighting, using the software Relux and then the modelling of the environment carried out using the software Fryrender. Table 6 shows the comparison of the summary of results obtained in the two scenarios. Figure 11 shows four frames of the simulation of dynamic lighting with natural biorhythm. Figure 12 shows the image of the simulation of standard lighting. Figure 13 shows the comparison of the variation of dynamic lighting with the standard lighting.

Table 6: Comparison between the standard and dynamic scenarios (Relux data).

\begin{tabular}{lll}
\hline & Standard Scenario & Dynamic Scenario \\
\hline Calculation algorithm used & High indirect fraction & \\
Height of evaluation surface & 1.75 & \\
Height of luminaire plane & 3.95 & \\
Maintenance factor & 0.80 & \\
Total luminous flux of all lamps & $348,300 \mathrm{~lm}$ & $235,200 \mathrm{~lm}$ \\
Total power & $4322 \mathrm{~W}$ & $2640 \mathrm{~W}$ \\
Total power per area $\left(695.72 \mathrm{~m}^{2}\right)$ & $15.93 \mathrm{~W} / \mathrm{m}^{2}$ & $9.73 \mathrm{~W} / \mathrm{m}^{2}$ \\
Average Illuminance $\left(E_{m}\right)$ & $339 \mathrm{~lx}$ & $1206 \mathrm{~lx}$ \\
Minimum Illuminance $\left(E_{\min }\right)$ & $100 \mathrm{~lx}$ & $773 \mathrm{~lx}$ \\
Maximum Illuminance $\left(E_{\max }\right)$ & $528 \mathrm{~lx}$ & 0.32 \\
Uniformity $\left(E_{\text {min }} / E_{m}\right)$ & 0.29 & 0.15 \\
Uniformity $\left(E_{\min } / E_{\text {max }}\right)$ & 0.18 & \\
\hline
\end{tabular}
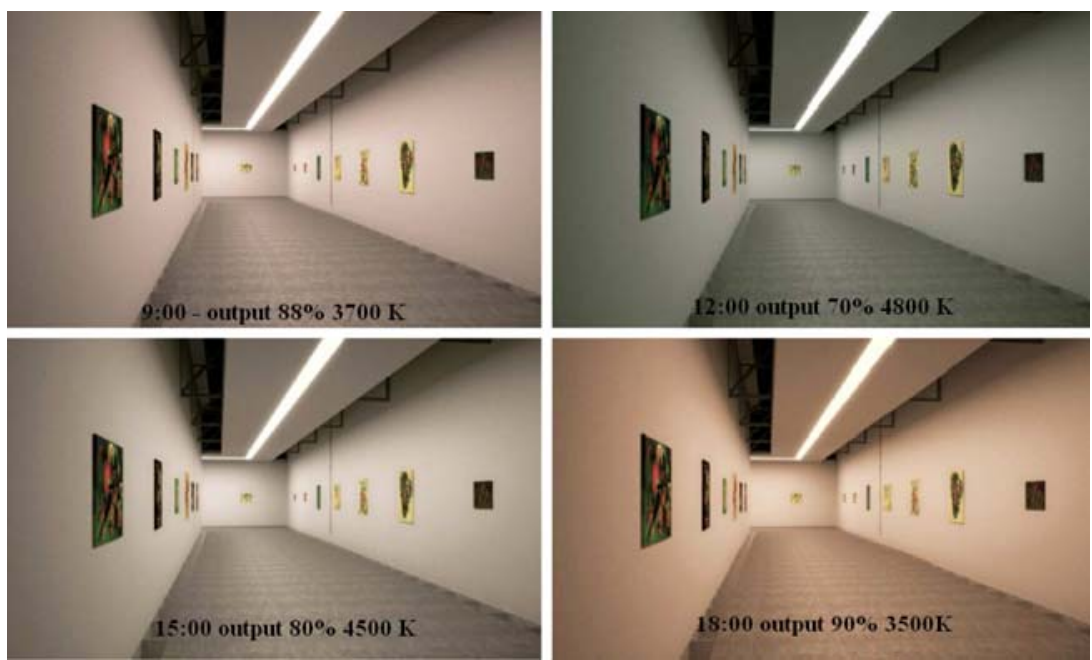

Figure 11: The images of gallery with dynamic lighting system at different hours of the day. 


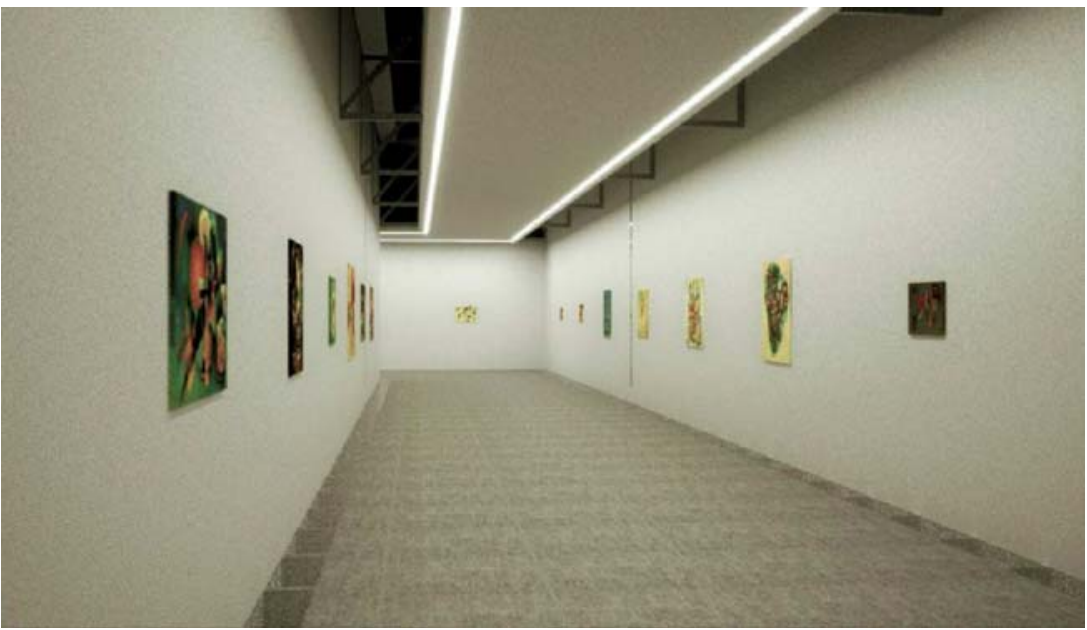

Figure 12: The images of gallery with standard lighting system.

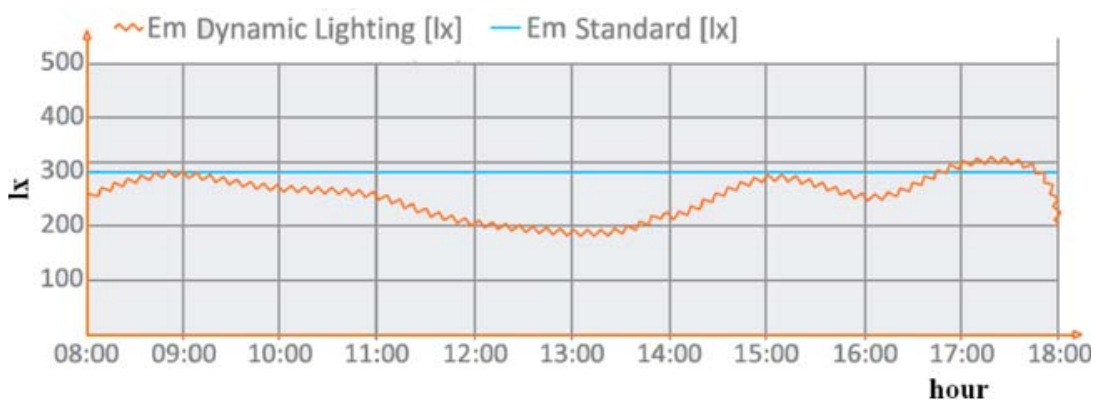

Figure 13: Comparison of illuminance between the dynamic lighting trend and standard lighting system.

\section{THE ASSEMBLY ROOM}

As stated in the previous section, the modelling of the exhibition hall was performed, applying both the standard lighting system and the dynamic lighting system.

In the dynamic lighting simulation, the assembly room equipment has been arranged in three rows of three Philips type lighting fixtures, Savio model, version for mounting on the ceiling containing lamps 35W (TBS770-3xTL5-35W/865/827/865 HFD AC-MLO). In the standard lighting simulation, the assembly room equipment has been arranged in three rows of three of Philips type lighting fixtures, Savio model, version for mounting on the ceiling containing lamps 35W (TCS760-3xTL5-35W HFP AC-MLO). The horizontal and vertical illuminance levels both for the standard scenario and the dynamic scenario were calculated using the human rhythm, and not taking into account the daylighting, using the software Relux and then the environment was modelled using the software Fryrender. Table 7 shows the comparison of the summary of results obtained in the two scenarios. Figure 14 shows four frames of the simulation of dynamic lighting with natural biorhythm. Figure 15 shows the image of the simulation of standard lighting. Figure 16 shows the comparison of the variation of dynamic lighting with the standard lighting.

It is possible to observe the dynamic character of light during the day in terms of brightness and warmth helps people enjoy the beneficial effects of natural light on the human body. 
Table 7: Comparison between standard and dynamic scenarios (Relux data).

\begin{tabular}{lll}
\hline & Standard Scenario & Dynamic Scenario \\
\hline Calculation algorithm used & High indirect fraction & \\
Height of evaluation surface & 0.75 & \\
Height of luminaire plane & 3.30 & \\
Maintenance factor & 0.80 & \\
Total luminous flux of all lamps & $59,400 \mathrm{~lm}$ & $85,509 \mathrm{~lm}$ \\
Total power & $693 \mathrm{~W}$ & $1044 \mathrm{~W}$ \\
Total power per area $\left(695.72 \mathrm{~m}^{2}\right)$ & $15.72 \mathrm{~W} / \mathrm{m}^{2}$ & $22.69 \mathrm{~W} / \mathrm{m}^{2}$ \\
Average Illuminance $\left(E_{m}\right)$ & $560 \mathrm{~lx}$ & $861 \mathrm{~lx}$ \\
Minimum Illuminance $\left(E_{\min }\right)$ & $268 \mathrm{~lx}$ & $412 \mathrm{~lx}$ \\
Maximum Illuminance $\left(E_{\max }\right)$ & $719 \mathrm{~lx}$ & $1100 \mathrm{~lx}$ \\
Uniformity $\left(E_{\min } / E_{m}\right)$ & 0.47 & 0.47 \\
Uniformity $\left(E_{\min } / E_{\max }\right)$ & 0.37 & 0.37 \\
\hline
\end{tabular}
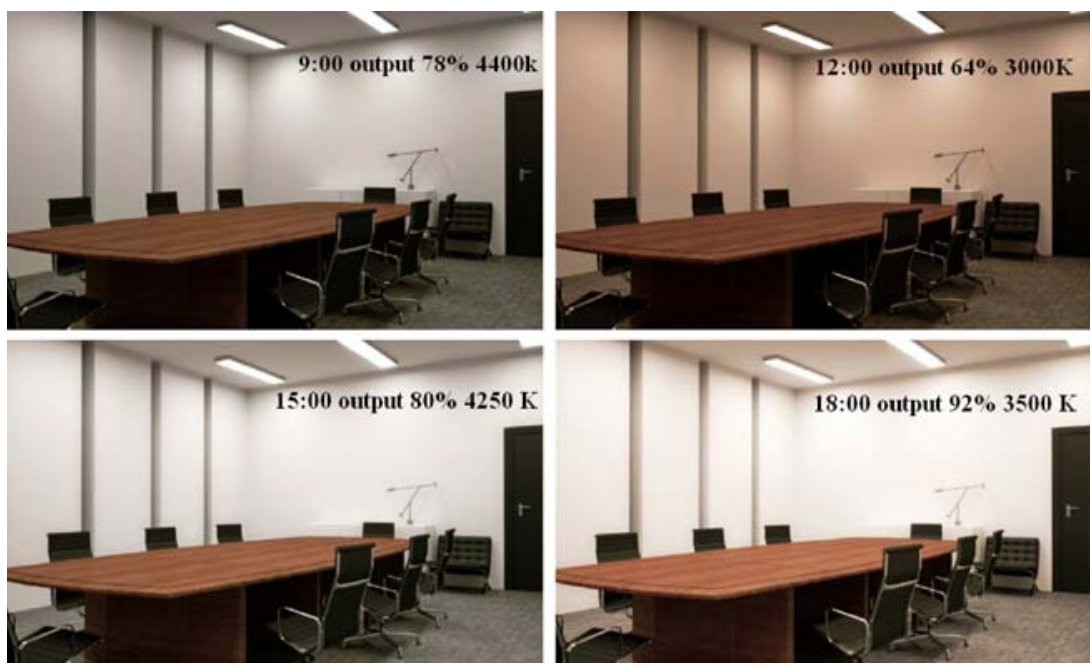

Figure 14: The images of exhibition hall with dynamic lighting system at different hours of the day.

\section{CONCLUSIONS}

The results of our study have shown that the use of dynamic lighting that changes the light during the day allows to obtain the following benefits:

- With flexibility in work spaces, the same rooms could be used by different people for different purposes at different times thanks to the possibility to change the dynamic scenario

- Improve people's general sense of well-being by reacting to their needs and specific situation at different times of the day

- Adapt the light to the physical condition, mood and work of the users

- New possibilities for artistic lighting of the exhibition spaces give them a feeling of open spaces

These benefits are especially valuable in modern offices where people and their ideas create value and human factors like motivation become a key factor to increase the 'productivity' in the workplace. 


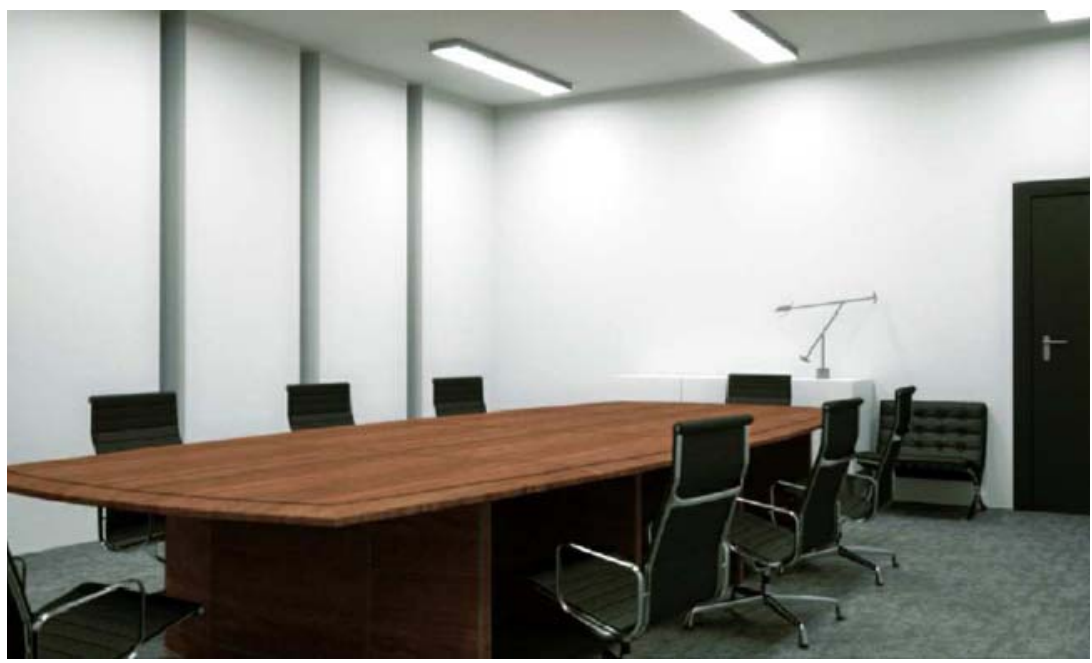

Figure 15: The images of Assembly room with standard lighting system.

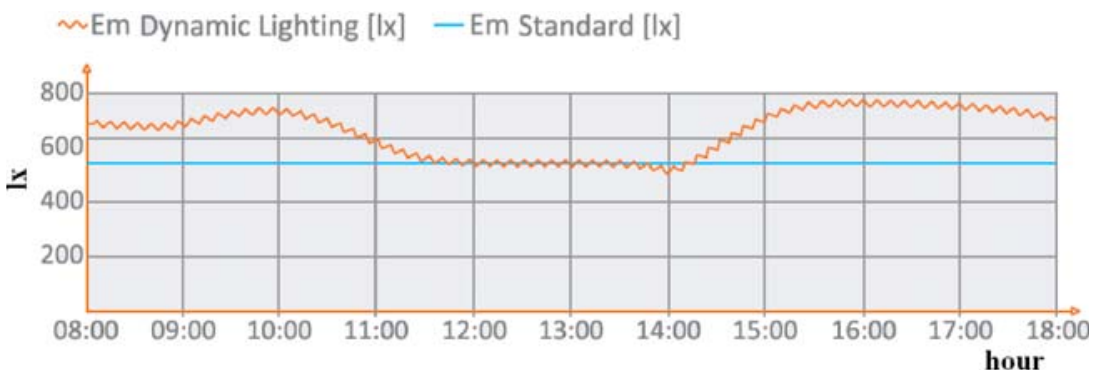

Figure 16: Comparison of illuminance between the dynamic lighting trend and standard lighting.

In terms of energy savings the cost of dynamic lighting system is minimum but not significant compared with that of the standard lighting system.

To summarise that the benefits from the dynamic lighting system have to balance the cost of the equipment of a dynamic lighting system which is more expensive compared with that of the standard system. The future research will have to verify the possible energy savings obtainable integrating the dynamic lighting with day-lighting systems.

\section{REFERENCES}

[1] Berson, D.M., Dunn, F.A., Takao, M. Phototransduction by retinal ganglion cells that set the circadian clock. Science, 295, pp. 10, 2002. doi: http://dx.doi.org/10.1126/science.1067262

[2] Dacey, D.M., Liao, H.W., Peterson, B.B., Robinson, F.R., Smith, V.C., Pokorny, J., Yau, K.W., Gamlin, P.D. Melanopsinexpressing ganglion cells in primate retina signal colour and irradiance and project to the LGN. Nature, 433, pp. 749-754, 2005. doi: http://dx.doi.org/10.1038/ nature 03387

[3] Gooley, J.J., Lu, J., Fischer, D., Saper, C.B. A broad role for melanopsin in nonvisual photoreception. J Neurosci, 23(18), pp. 7093-7106, 2003.

[4] Duffy, J.F., Wright, K.P., Jr. Entrainment of the human circadian system by light. J Biol Rhythms, 20(4), pp. 326-338, 2005. doi: http://dx.doi.org/10.1177/0748730405277983 
[5] Pauley, S.M. Lighting for the Human Circadian Clock. Recent research indicates that lighting has become a public health issue. Online article. Available from: http://www.darkskysociety .org/handouts/pauley.pdf [August 18 2006] 2004.

[6] Shanahan, T.L., Czeisler, C.A. 1991 Light exposure induces equivalent phase shifts of the endogenous circadian rhythms of circulating plasma melatonin and core body temperature in men. J Clin Endocrinol Metab, 73, pp. 227-235. doi: http://dx.doi.org/10.1210/jcem-73-2-227

[7] Lewy, A.J., Wehr, T.A., Goodwin, F.K., Newsome, D.A., Markey, S.P. Light suppresses melatonin secretion in humans. Science, 210, pp. 1267-1269, 1980. doi: http://dx.doi.org/10.1126/ science. 7434030

[8] Turek, F.W. Lighting up the brain [Editorial]. J Biol Rhythms, 14, pp. 171, 1999. doi: http:// dx.doi.org/10.1177/074873099129000551

[9] Van Cauter, E., van Coevorden, A., Blackman, J.D. Modulation of neuroendocrine release by sleep and circadian rhythmicity. In: Advances in neuroendocrine regulation of reproduction. Yen S, Vale W, eds. Norwell: Serono Symposia; pp. 113-122. References 116, 1990.

[10] Weibel, L., Follenius, M., Spiegel, K., Ehrhart, J., Brandenberger, G. Comparative effect of night and daytime sleep on the 24-hour cortisol secretory profile. Sleep, 18, pp. 549-556, 1995.

[11] Scheer, F.A.J.L., Buijs, R.M. Light affects morning salivary cortisol in humans. J Clin Endocrinol Metab, 84, pp. 3395-3398, 1999. doi: http://dx.doi.org/10.1210/jc.84.9.3395

[12] Leproult, R., Colecchia, E.F., L’Hermite-Balériaux, M., Van Cauter, E. Transition from Dim to Bright Light in the Morning Induces an Immediate Elevation of Cortisol Levels. J Clin Endocrinol Metab, 86, pp. 151-157, 2001. doi: http://dx.doi.org/10.1210/jc.86.1.151

[13] Späth-Schwalbe, E., Schöller, T., Kern, W., Kern, W., Fehm, H.L., Born, J. Nocturnal adrenocorticotropin and cortisol secretion depends on sleep duration and decreases in association with spontaneous awakening in the morning. J Clin Endocrinol Metab, 75, pp. 1431-1435, 1992. doi: http://dx.doi.org/10.1210/jc.75.6.1431

[14] Pruessner, J.C., Wolf, O.T., Hellhammer, D.H., Buske-Kirschbaum, A., von Auer, K., Jobst, S., Kaspers, F., Kirschbaum, C. Free cortisol levels after awakening: a reliable biological marker for the assessment of adrenocortical activity. Life Sci, 61, pp. 2539-2549, 1997. doi: http:// dx.doi.org/10.1016/S0024-3205(97)01008-4

[15] Clow, A., Thorn, L., Evans, P., Hucklebridge, F. The awakening cortisol response: methodological issues and significance. Stress, 7(1), pp. 29-37, 2004. doi: http://dx.doi.org/10.1080/ 10253890410001667205

[16] Higuchi, S., Motohashi, Y., Liu, Y., Ahara, M., Kaneko, Y. Effects of VDT tasks with a bright display at night on melatonin, core temperature, heart rate, and sleepiness. $J$ Appl Physiol, 94(5), pp. 1773-1776, 2003.

[17] Japanese white paper on information technology, The Ministry of Posts and Telecommunications, 1988 (In Japanese).

[18] Reiter, R.J., Richardson, B.A. Some perturbations that disturb the circadian melatonin rhythm. Chronobiol Int, 9(4), 314-321, 1992. doi: http://dx.doi.org/10.3109/07420529209064541

[19] Leppämäki, S., Haukka, J., Lönnqvist, J., Partonen, T. Drop-out and mood improvement: a randomised controller trial with light exposure and physical exercise. BMC Psychiatry, 4, pp. 22-32, 2004. http://dx.doi.org/10.1186/1471-244X-4-22

[20] McIntyre, I.M., Judd, F.K., Marriott, P.M., Burrows, G.D., Norman, T.R. Plasma melatonin levels in affective states. Int J Clin Pharmacol Res, 9(2), pp. 159-164, 1989.

[21] Henri Juslén, Improving healthcare with light, Philips Lighting.

[22] Brill, T.B., Lights interaction with art and antiquities, Plenum Press, New York, 1980.

[23] Frye, M., Light in museums and galleries, Concord Lighting Ltd: London, 1985.

[24] Banks, P.M., Moore, L.A., Liu C., Wu B., Dynamic visual acuity: a review. S.Afr. Optometry, 63(2), pp. 58-64, 2004. 